\title{
Research on the Inner Wall of the Blind Hole Drilling Device
}

\author{
Lin Zhu and Wei Huang ${ }^{*}$ \\ College of Mechanical Engineering, Xi`an Shiyou University, Xi`an 710065, China
}

\begin{abstract}
This article describes the structure and working principle of the blind hole drilling device through application in the production practice proving its feasibility. At present, electrical discharge machining and welding method are commonly used to solve the problem. However, these methods have low processing efficiency, low manufacturing precision and high cost defect. This paper developed an inner wall of the blind hole drilling device, similar to stand-alone machine accessories and adopted the bevel gear transmission which can directly be mounted on vertical or horizontal milling machine, completing the processing operations in few minutes. This device not only has high processing efficiency and accuracy, but it also greatly reduces the production cost.
\end{abstract}

Keywords: Blind hole drilling, Drilling, Inner wall of the blind hole, Structural design, XA6132 Horizontal milling machine, Transmission mode.

\section{INTRODUCTION}

Drilling is a common process in machining processing. Generally, it is divided into through hole drilling and the blind hole drilling, in which the deep hole drilling and the abnormal hole drilling belong to the hard machining process, requiring the use of special equipment and tools. For example, petroleum logging instrument for cylinder structure designs a blind hole generally on the inner hole wall as shown in Fig. (1) with hole $\varphi 12 \mathrm{~mm}[1]$.

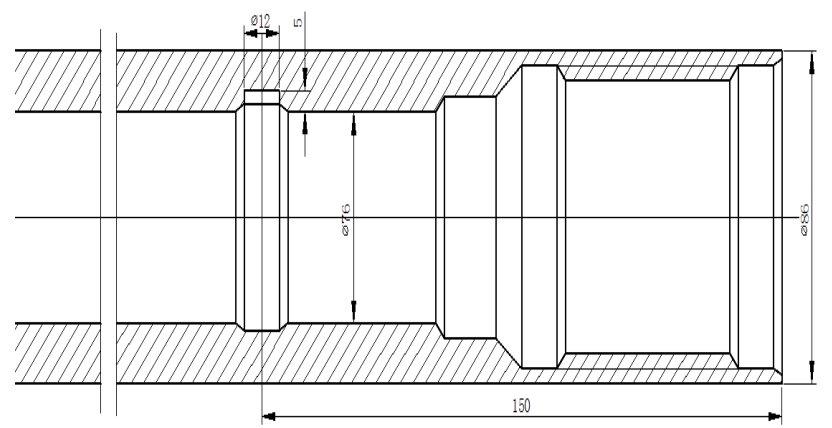

Fig. (1). The right end parts of petroleum logging instrument cylinder.

The blind hole drilling possesses the following problems:

(1) By the inner aperture $(\varphi 76)$ constraints, the blind hole drilling cannot be processed in the conventional machine, and the design of the special tools becomes more difficult [2].

(2) The overhang of special tool is longer and less rigid, which may cause easy knife fight.

(3) It is difficult to visually observe the cutting conditions but it is easy to block debris and knife fight [3].

*Address correspondence to this author at the College of Mechanical Engineering, Xi`an Shiyou University, Xi'an, 710065, China;

Tel: 15929968221; E-mail: 315701343@qq.com
At present, the blind hole processing usually adopts the following methods:

(1) Firstly, a hole is drilled opposite to the blind hole from the outer wall, and then the hole is welded after processing [4]. Although this method is simple and practical, the high temperature of welding causes the machined surface deformation and residual stress, influencing precision and service life of the parts.

(2) Using electrosparking process, this method can guarantee the machining quality, and does not damage machining accuracy [5]. However, due to the longer barrel length, generally it is difficult to locate the position of electrosparking machine. Moreover, electrosparking machining efficiency is lower, higher with processing costs.

Therefore, this study aimed at the inner wall of the blind hole drilling characteristics, to design a drilling device by means of horizontal or vertical milling machine, a convenient location and clamping on the barrel, but efficient completion of the blind hole drilling process reducing the production costs [6].

\section{THE STRUCTURAL DESIGN OF THE BLIND HOLE DRILLING DEVICE}

According to the structure of the hole wall, drilling device can use the following two kinds of transmission ways:

(1) A plurality of straight tooth cylindrical gear power transmission mode, as shown in Fig. (2). This transmission mode can complete the blind hole drilling task, but due to its power through multi-stage gear transmission, lower transmission accuracy and efficiency, it is less rigidly prone to vibration.

(2) Adopting the bevel gear transmission. This mode of transmission is through a pair of bevel gears which not only changes the direction of power but also improves the machining efficiency and tool rigidity. 


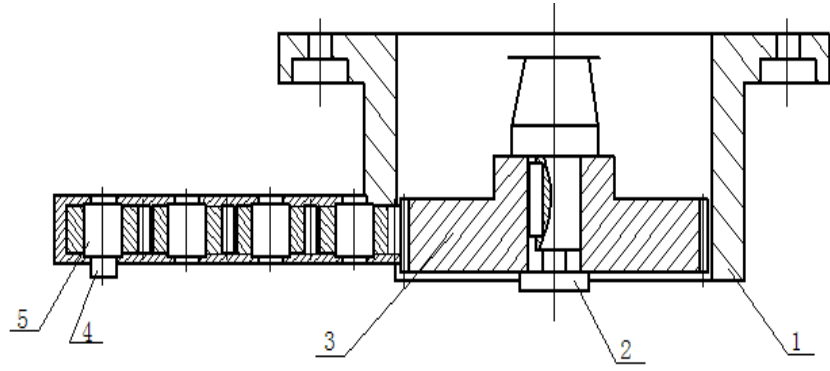

1-Box; 2-Machine tool spindle; 3-Big gear wheel; 4-tool; 5-Pinion

Fig. (2). The multi gear power transmission mode.

Based on the above analysis [7], bevel gear transmission mode and structure design were adopted. The blind hole drilling device is mainly composed of a long shaft, a short shaft, a pair of bevel gear and a keyway milling cutter. By connecting with the universal vertical milling machine or horizontal milling spindle (with universal milling head), power passes through the long axis, bevel gears and short axis finally to the tool to complete the blind hole drilling. Its structure is shown in Fig. (3).

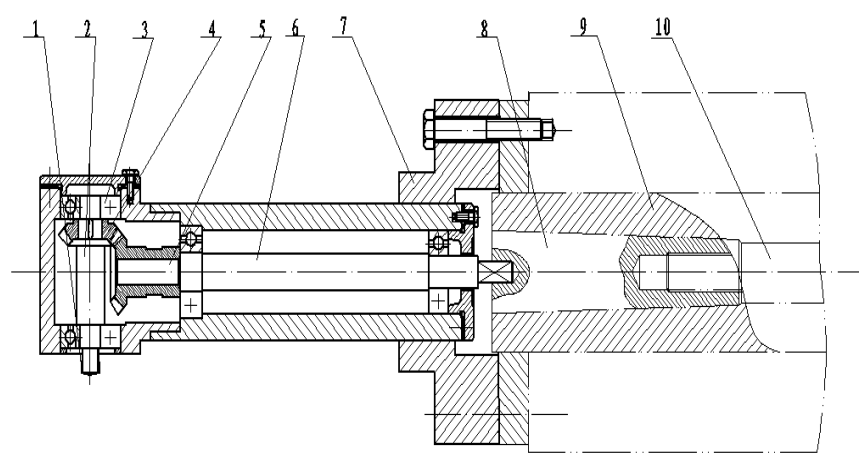

1-Tool; 2-The driven shaft; 3-Bearing; 4-Driven bevel gear; 5-Driving bevel gear; 6-Driving shaft; 7-Flange; 8-The cone sleeve; 9-Machine tool spindle; 10-Pull rod

Fig. (3). The inner wall of the blind hole drilling device structure.

As the inner wall diameter is of only $\varphi 76 \mathrm{~mm}$, it makes the size of the blind hole drilling devices more restricted, not only to achieve a compact overall structure, but also to ensure that the gear has sufficient strength [8]. Bevel gear drive process generally requires consideration of tooth contact fatigue strength and tooth root bending fatigue strength. The former is mainly concerned with the apex and the latter is only affected by the modulus. Through the study of the nature of the discovery process blind holes, it has been observed that blind holes do not belong to conventional machining operations. the focus should be on the bending fatigue strength as the application of frequency is not high and the tooth root is broken. In other words, it should increase the modulus gear, ensuring compliance with the requirements of the modulus gear.

The requirement of the diameter of blind hole machined parts is $\varphi 12 \mathrm{~mm}$, with a depth of $5 \mathrm{~mm}$. Therefore, the size of the tool and the supporting bearing specifications and dimensions which match with the tool are roughly determined. From the relationship between the structure as shown in Fig. (3), taking into account the driven bevel gear, assembly must be installed by a bearing hole, so that the size of the outer bearing diameter restricts the driven bevel gear. Straight shank keyway cutter is connected by threads and short shaft without affecting the normal drilling tool premises. However, the amount of drive shaft extending should be minimized in order to determine the positioning surface in the threaded end of the tool. There is no special requirement for the cutting speed; therefore, the design of the transmission gear ratio is set to $1: 1$. Thus, the driving and driven wheels may take the same diameter, in accordance with the actual status of the spatial location. After determining the transmission ratio, the size of the outer diameter of the driving and driven wheels can be roughly determined according to the bearing size, so that the transmission part of the device size is approximately determined.

The next question is how to choose the modulus and teeth. Due to space constraints, the diameter is not too large, and in order to increase the modulus $\mathrm{m}$, tooth number $\mathrm{Z}$ is reduced which is taken as 15 , which is smaller than the smallest teeth 17 and prevents the undercut but is higher than the value of 12 for guaranteeing that the undercutting is avoided. Although this choice may have some influence on the stability of device, the strength is increased and the device can ensure its normal use. The modulus $\mathrm{m}=2$ can be checked as follows:

$F_{c} \cos \theta+G \sin \theta \leq F_{f}=\left(G \cos \theta-F_{c} \sin \theta\right) f$

In the formula:

$K-$ coefficient of load, taken as 1.1 ;

$T$ - torque of the gear under the operation., The size of 9450 (drilling for $14 \mathrm{~mm}$ ), $\mathrm{N} \cdot \mathrm{mm}$;

$\Phi_{R}$ — tooth breadth coefficient, taken as 0.3 ;

$Y_{F a} Y_{S a}$ the product of tooth shape coefficient and Stress correction coefficient, taken as 3;

The ultimate bending strength of gear is $380 \mathrm{MPa}$, and from the figure, the bending fatigue life factor is obtained as $K_{F N}=0.88,[\sigma]_{F}=K_{F N} \times \sigma_{F} / S=0.88 \times 380 / 1.4=238.86 \mathrm{MPa}$.

Then $m \geq 1.96$, thus $m$ is taken as 2 . The average modulus of bevel gears: $F_{c}=\frac{m u^{2}}{R}, m_{m}=1.66$.

Therefore, parameter selection of the above design can meet the strength requirements.

In addition, the structure is also considered as the driving wheel and the transmission shafts are made into a whole, increasing the strength and also simplifying the processing and the assembly process.

\section{CONNECTION WITH THE MACHINE}

In practical application, the device is connected by the milling machine to complete the blind hole drilling. As shown in Fig. (3), the device through the conical sleeve is connected with the drilling tool axis, having directly installed in the universal vertical or horizontal milling machine and conical sleeve friction is generated by rod tension transfer machine tool spindle torque. In addition, the drilling device through flange is fixed on a milling machine, 
which has the advantages of simple structure, convenient assembly and disassembly.

\section{THE TEST}

In order to verify the feasibility of the device, the inner wall of the blind hole processing device was tested. With the help of XA6132 horizontal milling machine (with universal milling head, the spindle rotates to the direction parallel to the length of the table) under the conditions of $150 \mathrm{r} / \mathrm{min}$ speed, $1 \mathrm{~mm} / \mathrm{min}$ feed rate, the parts are processed by the test which is conducted in the specified location of $\varphi 12 \mathrm{~mm}$, and $5 \mathrm{~mm}$ depth blind hole machining. The processing site is shown in Fig. (4).

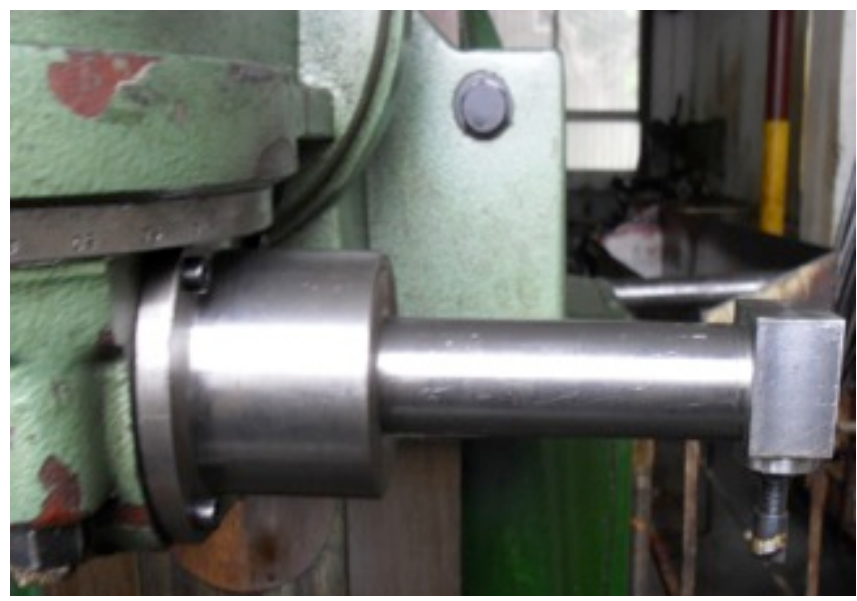

Fig. (4). The processing site of the test.

\section{CONCLUSION}

Through the above study, it can be observed that the device can complete the processing operation in a few minutes as the machining efficiency and accuracy are higher, greatly reducing the production cost and also providing a convenient method for blind hole processing. By changing the cutter, the device can also process other inner blind holes which have the same requirements but in a different diameter. So that the working of the blind holes in this particular process become easy to implement.

\section{CONFLICT OF INTEREST}

The authors confirm that this article content has no conflict of interest.

\section{ACKNOWLEDGEMENTS}

Declared none.

\section{REFERENCES}

[1] Y. Jiang, and H. Miao, "Method for processing large annular inner blind hole parts", Mechanical Design and Manufacturing, vol. 4, 1998 .

[2] Z. Gong, "The tool to process the blind hole", Mechanical Workers. Cold Working, vol. 1, 008, 1993.

[3] K. Weinert, D. Biermann, and S. Bergmann, "Annals of the CIRP", vol. 56, pp. 105-108, 2007.

[4] S.Q. Wang, and L. Zhu, "The Deep Hole Processing Technology", Press of North-West Polytechnic University, pp. 52-68, 2003.

[5] R.Y. Chen, "Theory of metal cutting", China Machine Press, pp. 23-26, 2003.

[6] L. Zhu, and K.Y. Wang, Aerospace Materials \& Technology, vol. 3, pp. 54-56, 2005.

[7] D. Opalla: Hochleistungs bohren metallischer Werkstoffe mit Wendel bohrern Dissertation Universität Dortmund Vulkan verlag, Essen 2003.

[8] K. Weinert, D. Biermann, and S. Bergmann, Annals of the CIRP, vol. 56, pp.105-108, 2007. 